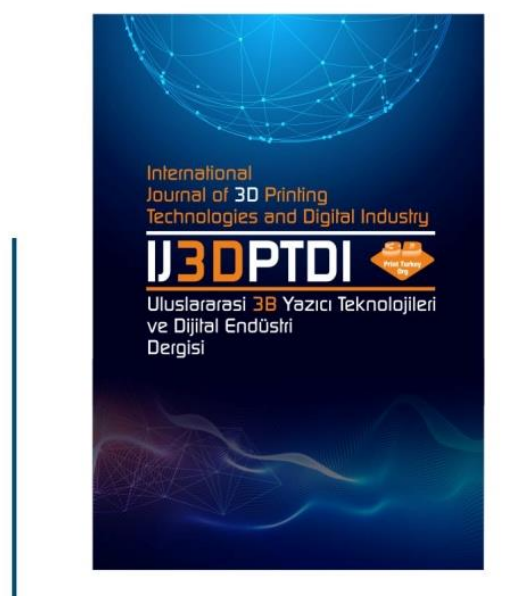

ULUSLARARASI 3B YAZICI TEKNOLOJILERI

VE DIJITAL ENDÜSTRI DERGISI

INTERNATIONAL JOURNAL OF 30 PRINTING TECHNOLOGIES AND DIGITAL INDUSTRY

IS5N:2602-3350 [Online]

URL: https://dergipark.org.tr/ij3dptdi

\title{
EFFECT OF WIRE ELECTRICAL DISCHARGE MACHINING ON THE SURFACE OF EBM-ADDITIVE MANUFACTURED NITI ALLOYS
}

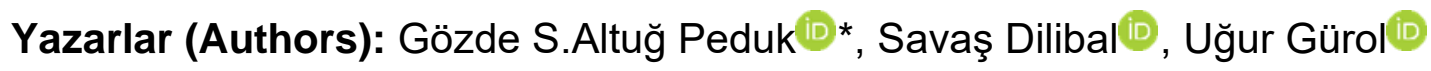

Bu makaleye şu şekilde atıfta bulunabilirsiniz (To cite to this article): Peduk G.S., Dilibal S., Gurold U. "Effect Of Wire Electrical Discharge Machining On The Surface Of Ebm-Additive Manufactured Niti Alloys" Int. J. of 3D Printing Tech. Dig. Ind., 5(3): 606613, (2021). 


\title{
EFFECT OF WIRE ELECTRICAL DISCHARGE MACHINING ON THE SURFACE OF EBM-ADDITIVE MANUFACTURED NITI ALLOYS
}

\author{
Gözde S.Altuğ Peduk ${ }^{\mathrm{a}}(\mathbb{D})$ *, Savaş Dilibal ${ }^{\mathrm{b}, \mathrm{c}}(\mathbb{D})$ Uğur Gürol $^{\mathrm{d}, \mathrm{e}}$ (D) \\ a North Raleigh Technologies, USA \\ b Istanbul Gedik University, Mechatronics Engineering Department, Kartal, Istanbul, TURKEY \\ c Istanbul Gedik University Robot Technology Research and Application Center, Kartal, Istanbul, TURKEY \\ d Gedik Welding Company, Research and Development Center, Şeyhli, Pendik, Istanbul, TURKEY \\ e Istanbul Gedik University, Metallurgical and Material Engineering Department, Kartal, Istanbul, TURKEY \\ *Corresponding author: gsultan.altug@gmail.com
}

(Received: 03.07.2021; Revised: 04.11.2021; Accepted: 24.12.2021)

\begin{abstract}
Nickel-titanium (NiTi) shape memory alloys are used in varied engineering products, such as biomedical device and mechatronic actuator applications. The conventional machining technology are utilized in the limited fields due to their effects on the hardness and brittleness of the machined alloys. However, the wire electrical discharge machining (WEDM) technology is one of the most preferred postprocessing tool to obtain a surface with high quality. The electrical current and voltage values with pulse on and pulse off time are the crucial parameters for WEDM. These parameters should be optimized before wire electrical discharge machining process. Electron beam melting (EBM)-based additive manufacturing of the nickel-titanium powders provides obtaining bulk NiTi shape memory alloys using high energy electron beams. In this study, the application of WEDM which is used as a post-processing tool is evaluated for the EBM-based additive manufactured NiTi samples. Additionally, the scanning electron microscopy, elemental analysis and microhardness characteristics results of the wire electrical discharge machined NiTi samples are carefully investigated.
\end{abstract}

Keywords: Additive manufacturing, Electron beam melting, Nickel-Titanium Alloy, Wire electrical discharge machining

\section{INTRODUCTION}

Wire electrical discharge machining (WEDM) is one of the most preferred thermo-electric manufacturing process for post processing of the additively manufactured products. This machining process is exceptionally used for machining of the hard materials such as titanium alloys, Inconel series, case-hardening steels, cemented carbide, and conductive ceramics. An electrical spark is generated between the WEDM wire and the specimen during the wire electrical discharge machining. The wire which is used as the tool electrode is mainly made of copper, tungsten, or brass. When the sparking occurs between two electrodes, material is cut in desired shape and detached from the surface.

Wire electrical discharge machining process offers an efficient alternative for the engineering applications comparing to conventional manufacturing techniques. Since this machining process is fully automated, the machining parameters of the thermal process are controlled to eliminate the damage formation and distortion on the surface of the additively manufactured parts. This machining process is commonly employed to produce the parts and components in several fields, such as aerospace, automotive, and electronic industries [1,2].

NiTi shape memory alloys, also known as nitinol, are a promising material to meet the requirements for a broad-spectrum of engineering applications in the biomedical, aerospace, and mechatronic fields. Many studies have been done to reveal their thermo-mechanical mechanisms which occur through the 
two significant reversible phases; a B2 structured austenite, and a B19' structured martensite phases [34]. The thermoelastic martensitic phase transformation from the main $B 2$ phase to the B19' crystal structure initiates the shape memory effect and the superelastic response depending on the applied pressure or temperature. Additionally, many efforts have been made for the determination of the damping and fatigue resistance properties of the NiTi shape memory alloys. These studies stimulated the inspirations of novel applications in many universities, research centers, and industries that resulted in successful patents, such as stent and orthodontic braces in the biomedical field, actuators in robotics, and corrosion-resistant applications in marine systems [5-6]. The manufacturing of the NiTi product is mainly achieved by casting, conventional powder metallurgy, and additive manufacturing technologies. The casting technology is referred as the most applied process to manufacture NiTi components. It consists of vacuum induction melting (VIM) and vacuum arc remelting (VAR). Among these manufacturing methods, while VIM provides simple operation, sufficient chemical homogeneity, high processing costs, carbon contamination, and rapid grain growth limits the potential of the NiTi product. Due to the difficulties in casting, hot-cold processing and machining, limited number of commercial products are presented to the market. Particularly, the amount of nickel content in the chemical composition has crucial influence on the martensitic phase transformation since the increase of transformation temperature can rapidly drop below room temperature with increasing Ni-content in the composition [7-9]. Powder metallurgy-based processes are categorized into two methods. These are conventional powder metallurgy and additive manufacturing. Additive manufacturing techniques consist of Selective Laser Sintering, Selective Laser Melting (SLM), and Electron Beam Melting $(E B M)$. Although conventional powder metallurgical methods possess low cost with high production rate, the formation of the secondary phases limit the utilization of these methods for the production of the NiTi products.

On the other hand, the processing steps involve two main elements which are the process inputs, and the process outputs through the additive manufacturing. In the process inputs, hardware-software conditions, build chamber preparation, powder loading, powder quality, CAD modeling of the desired part, uploading the STL file to the machine, and the layer thickness should be considered. Completion of the build according to the geometrical compatibility and elimination of defects in the microstructure of the final product accompanied by the physical and mechanical properties are described in the process outputs. Especially, the defects and their formation mechanisms determine the quality of the additively manufactured parts. Porosity, delamination, residual stresses, and cracking are the most common defects. Their quantities can be eliminated significantly with the applied process inputs in the additive manufacturing technologies [10].

After manufacturing of the NiTi component, they need to be formed into desired geometrical shape. The forging, swaging, and drawing techniques can cause large deformation due to the high operating temperatures. In order to achieve a stable shape memory or superelastic response in the material, thermomechanical cycling followed by annealing and ageing treatment should be applied as a secondary processing method [11]. The desired-shaped NiTi components are removed from the main workpiece by micro and macro separation machining methods as given in Figure 1. Although coating of the cutting tool increases its life span severing, turning, and grinding methods can cause high wearing owing to the increased hardness, and high surface heat on the surface of the materials. On the other hand, the laser cutting is particularly used for the biomedical NiTi components since the process offers flexible solutions to create complex-shaped geometries without having tool wear, and high mechanical stress on the NiTi workpiece [12]. 


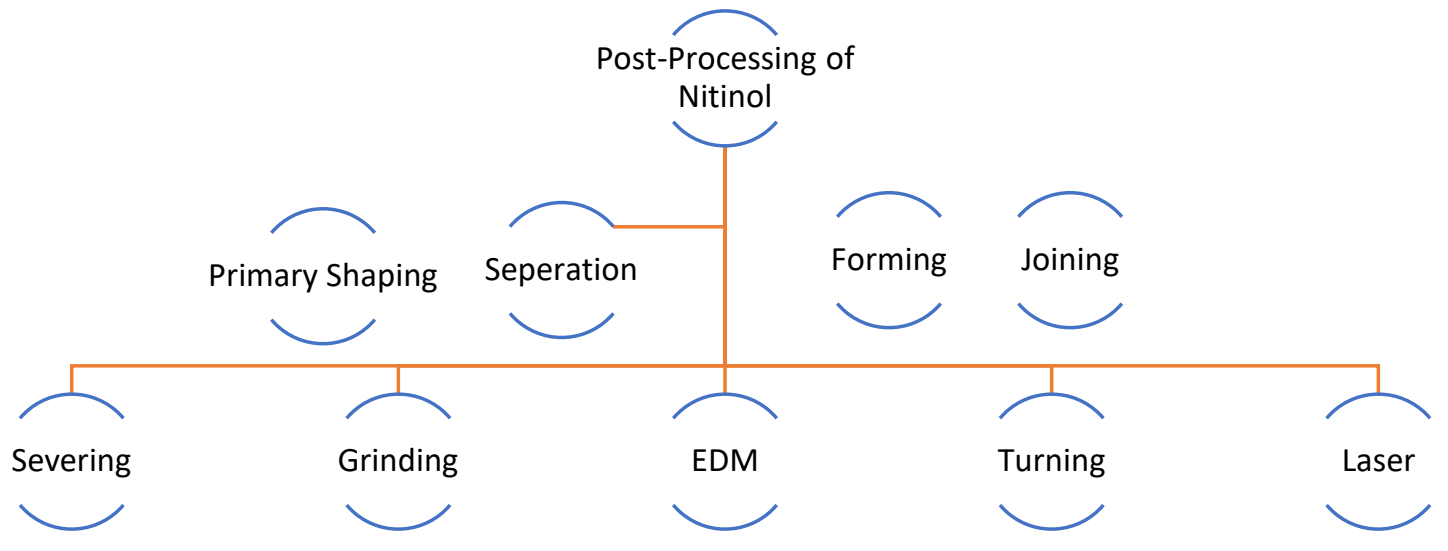

Figure 1. Post-processing types of the NiTi workpiece

The WEDM process is considered as a vital post-processing method for machining of the NiTi workpieces. With the electrical pulse generated via power supply, the dielectric liquid insulating property can be fluctuated instantly. A micro spark occurs between the WEDM's wire and the workpiece. The occurred spark generates a small molten metal pool on the workpiece. Upon stopping of the electrical pulse, the spark disappears. A small crater occurs in the molten metal part on the workpiece. Studies shows that during micro-EDM machining, constituent elements of the tool material are deposited on the sub-surface and coat an antibacterial layer by controlling the process parameters including dielectric fluid, and pulse energy. On the other hand, the wire electrical discharge machining offers various post processing options, such as processing the holes, sample preparation for tensile and compression tests to obtain the final geometry of the workpiece $[13,14]$. The surface finish and dimensional accuracy of specimen are significantly vital for the engineering applications. In the literature, it is found that the surface roughness value increases with increasing pulse duration, opencircuit voltage, and wire speed. In contrast, the surface roughness value decreases with increasing dielectric fluid pressure [15].

In this study, the application of WEDM which is used as a post-processing tool is examined for the EBM-based additive manufactured bulk NiTi specimen [16-17]. The process parameters are unveiled during the experimental study. In addition to the process parameters, the scanning electron microscopy and hardness characteristics results of the wire electrical discharge machined as-built NiTi samples are carefully investigated.

\section{EXPERIMENTAL PROCEDURE}

In this study, the NiTi samples which were fabricated using Arcam Q10Plus Electron Beam Melting machine in vacuum environment from pre-alloyed powders are prepared for the micro-tensile test process. The machining process was performed on the Accutex AU-300IA wire-EDM cutting machine that consists of an electrode, a dielectric tank with a dielectric circulation and filtration equipment, a programming unit, and a power supply. The wire electrode material which was selected as brass wire with diameter of $0.30 \mathrm{~mm}$ was used through the cutting process. The wire electrical discharge machine settings of pulse duration (t), servo voltage (SV), and wire tension (wt) were used in the WEDM process.

The wire-EDM method was conducted to cut the NiTi samples into dog-bone shaped tensile specimens and cyclic specimens according to ASTM STP1329 as seen in Figure 3. The EBM-based additive manufactured NiTi samples with the dimensions of 150x400x130 $\mathrm{mm}$ are utilized as a workpiece in the cutting process. The CuZn37 brass wire with the diameter of $0.30 \mathrm{~mm}$ was used in the experimental studies. The pulse frequency is equal to the sum of pulse on time and pulse off time. Pulse duration, open circuit voltage, and wire speed were selected as the input parameters. Additionally, the surface roughness was selected as an output parameter. Vicker microhardness (HV) test were conducted on the NiTi samples using a fully automatic hardness device (DuraScan-70 G5) with $1 \mathrm{~kg}$ load and dwell time 
of $15 \mathrm{~s}$ to analyze the hardness of the wire-EDM surfaced samples. Moreover, X-Ray Spectrometer (Rigaku ZSX Primus II) were utilized for elemental analysis in the EBM-based additive manufactured NiTi sample cross sections in percentage weight.
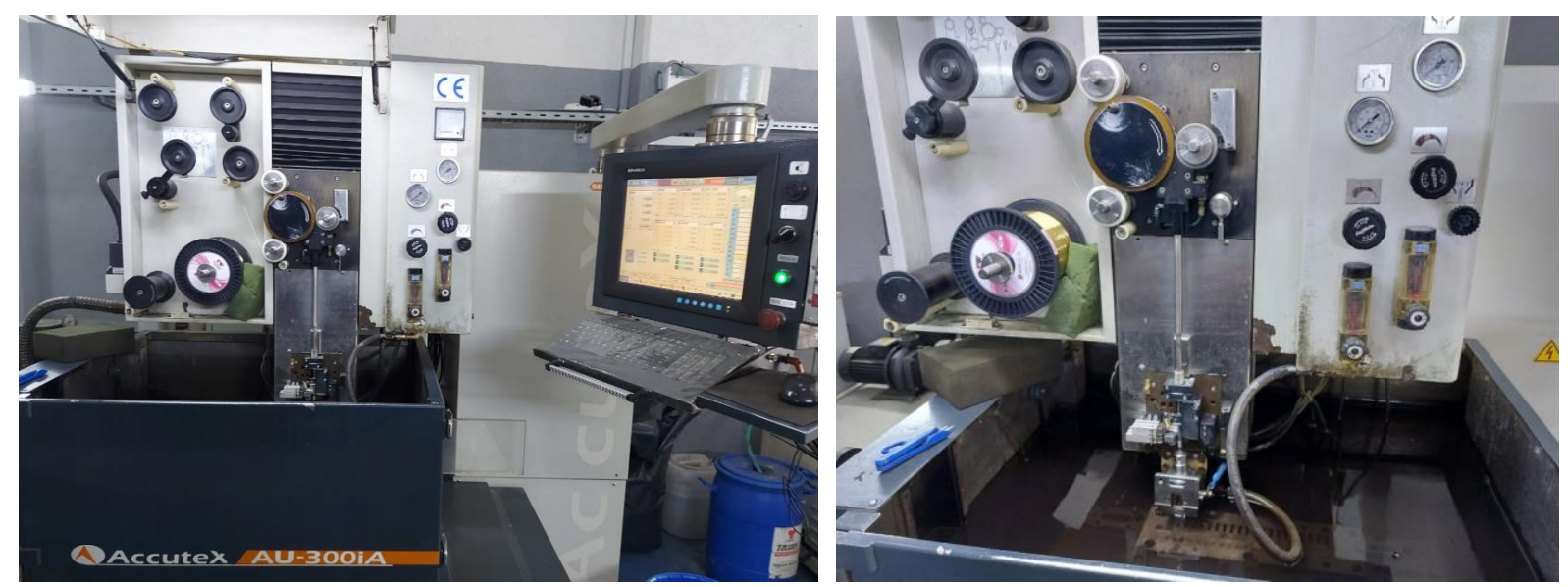

Figure 2. Accutex AU-300IA wire-EDM cutting machine

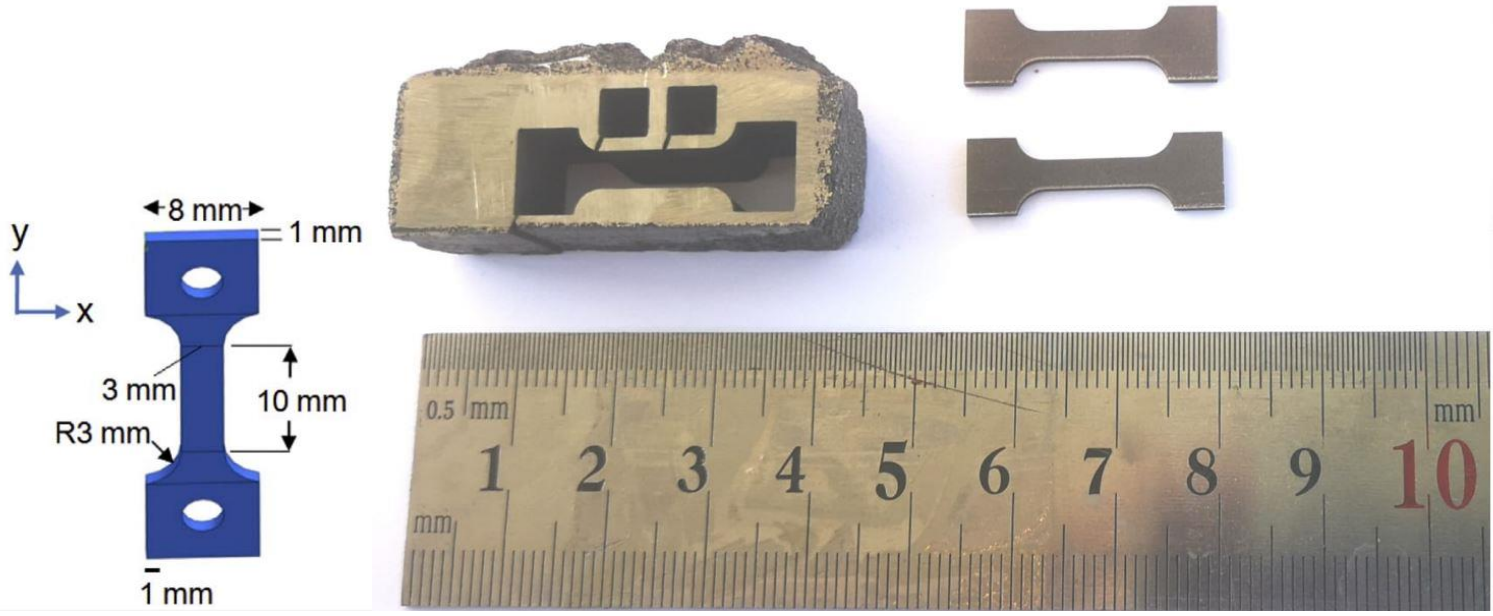

Figure 3. Geometries of the wire electrical discharge machined tensile specimen.

The significant parameters which affect the performance of the WEDM were unveiled during the experimental analysis. The experimental results revealed that pulse characteristics, dielectric property, electrode type and workpiece thermal characteristics are the vital parameters for obtaining efficient wire electrical discharge machining process. Figure 4 shows the details of the effective parameters for the performance of the wire-EDM process.

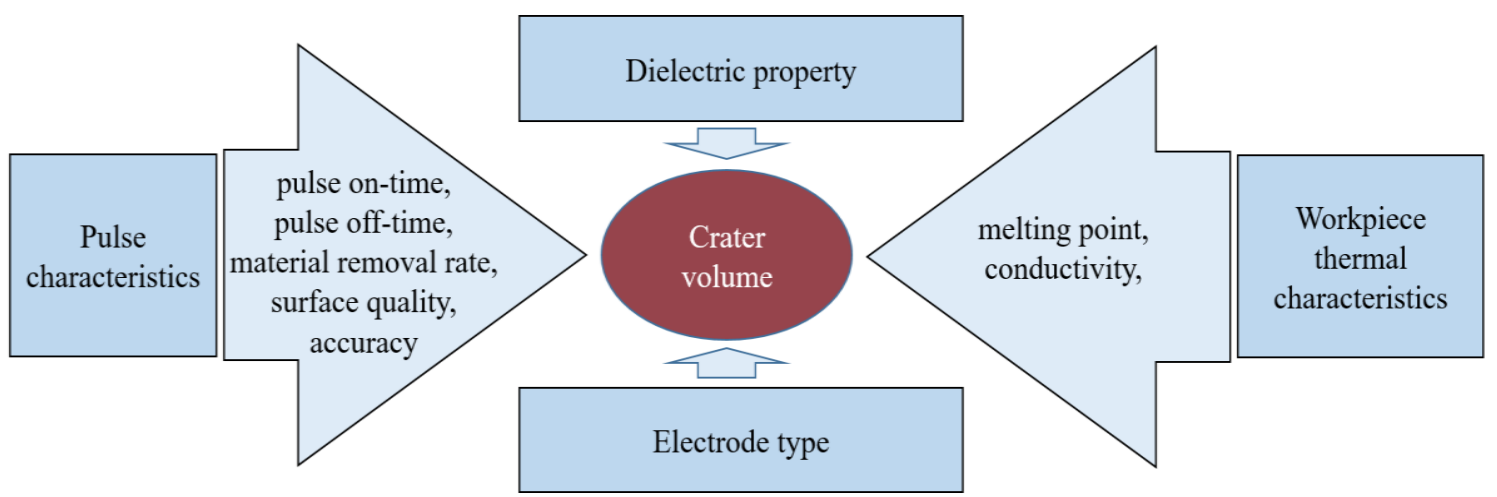

Figure 4. Main effective parameters affecting the performance of the WEDM 
The selected pulse on, pulse off, voltage, surface roughness, and offset values were the substantial input parameters in the process. The optimized cutting parameters are given in Table 1.

Table 1. Wire electrical discharge machining parameters.

\begin{tabular}{|c|c|c|c|c|c|}
\hline Pulse on & Pulse off & $\begin{array}{c}\text { Wire } \\
\text { tension }\end{array}$ & Servo Voltage & $\begin{array}{c}\text { Surface } \\
\text { roughness Sa }\end{array}$ & Offset \\
\hline $16 \mu \mathrm{s}$ & $8 \mu \mathrm{s}$ & $16 \mathrm{~N}$ & $40 \mathrm{~V}$ & $2.5 \mu \mathrm{m}$ & $0.1990 \mathrm{~mm}$ \\
\hline
\end{tabular}

\section{RESULTS AND DISCUSSION}

Elemental analysis and the high-resolution scanning electron microscope examinations were carried out on the WEDM machined specimen. Figure 5 shows the mapping position and corresponding elemental maps. It should be noted that the $\mathrm{Cu}$ element was detected in the elemental analysis in addition to $\mathrm{Ni}$ and Ti on the surface of the WEDM machined specimen while it was not present on the original specimen. Roth et al. reported the $\mathrm{Cu}$ and $\mathrm{Al}$ contamination on the nitinol surface after WEDM cutting process. It was stated that a recast layer is formed on the sample from the wire electrode material during the WEDM process [18].
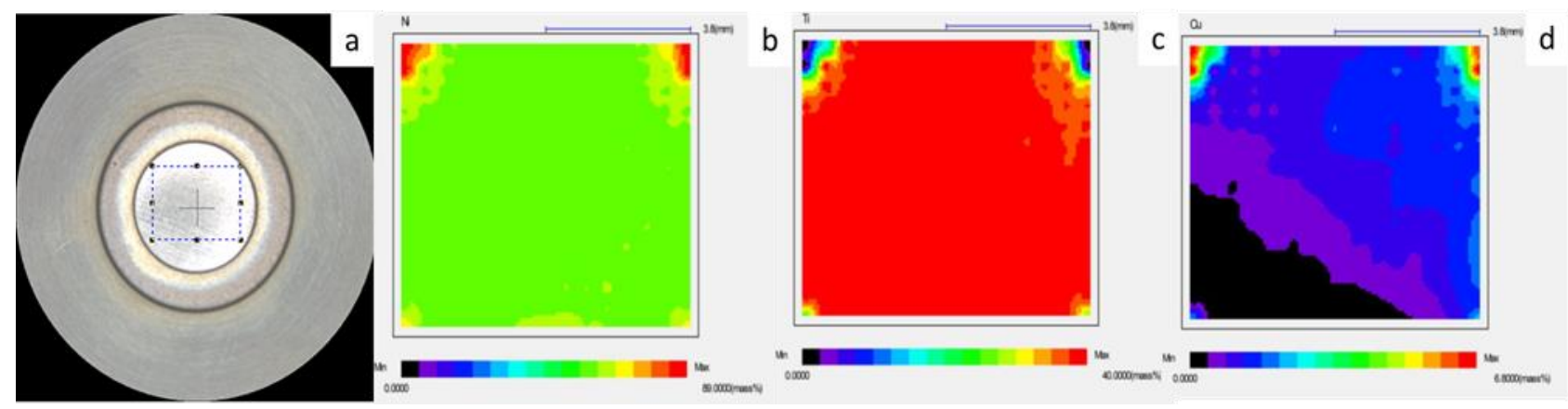

Figure 5. a) Elemental analysis mapping position setting of NiTi sample after WEDM, corresponding elemental maps of b) $\mathrm{Ni}, \mathrm{c}$ ) $\mathrm{Ti}, \mathrm{d}$ ) $\mathrm{Cu}$ of machined specimen

The micrographs of the NiTi samples are investigated using the scanning electron microscopy to observe their surface characteristic after wire electrical discharge machining process. Figure $6 \mathrm{a}$ and $6 \mathrm{~b}$ show the overall micrographs of the as-built NiTi samples. The scanning electron microscopy micrographs are taken from different locations of the NiTi samples. In the direction of solidification on the as-built sample, initially the section from the top layer to the center and then from the center to the first layer were examined in two different areas.
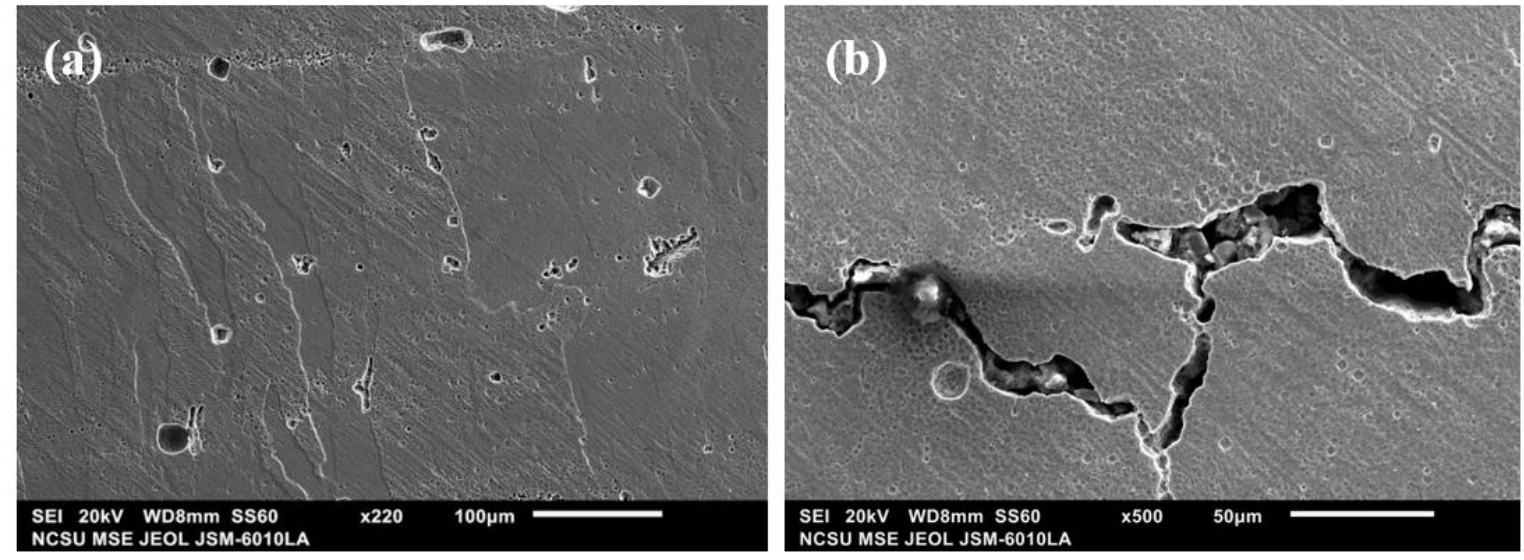

Figure 6. SEM micrographs of the NiTi samples; a) Horizontal specimen, b) Vertical specimen 


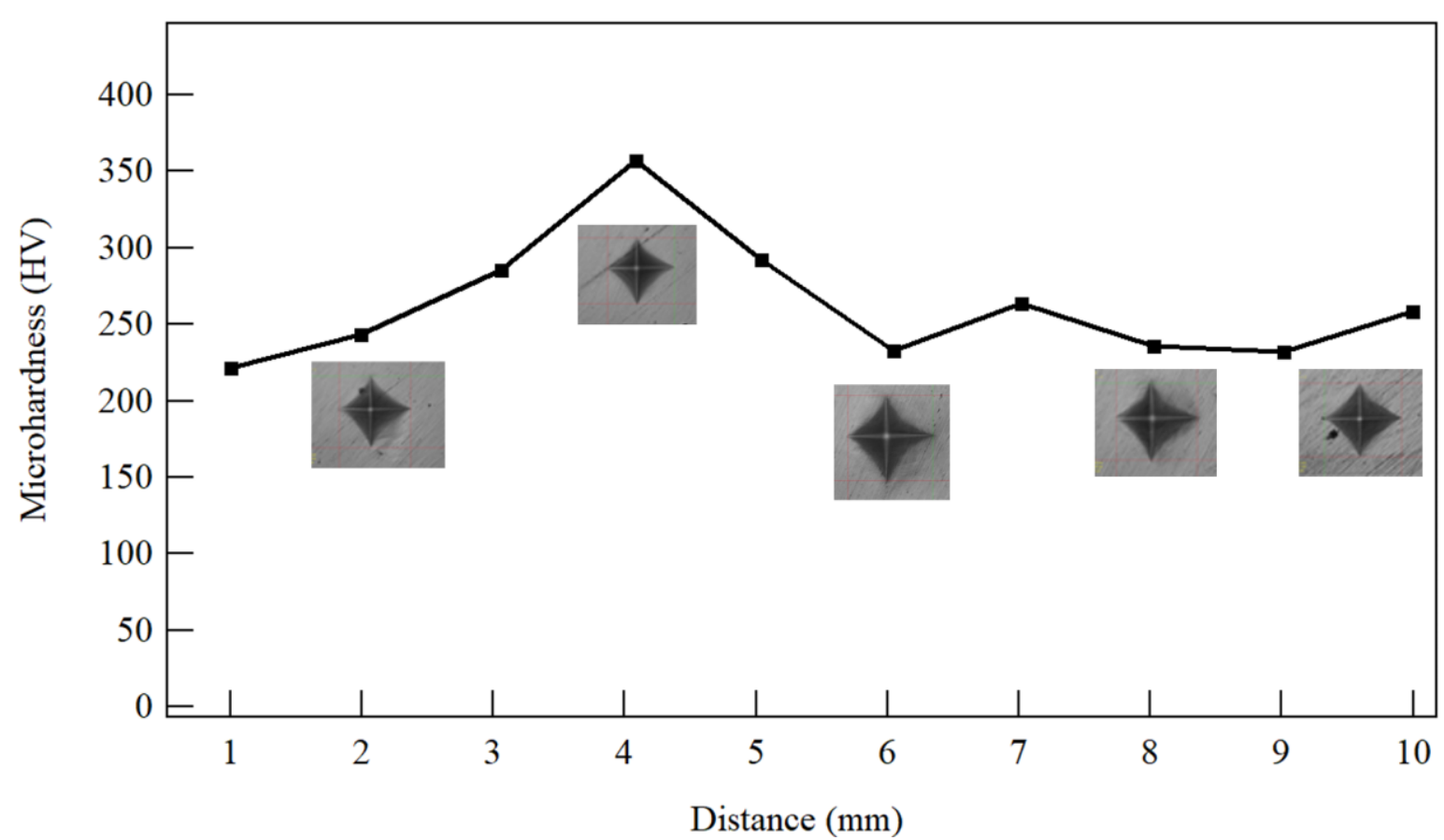

Figure 7. Vickers microhardness (HV1) distribution along the wire-EDM surfaced samples.

The scanning electron microscopy results show that a homogeneous solidification, and columnar grain structure are clearly observed along the build direction as seen in Figure 6a. In addition, it is observed that a full solidification was achieved during the melting of the layers. An irregular-shaped porosity in different locations is also observed in the micrographs as seen in Figure 6b. Roy et al. conducted an experimental study using nitinol-60 alloy to observe the responses of the machine parameters such as machining speed, and surface roughness during the WEDM process. It was concluded that due the high machining temperatures up to $1200{ }^{\circ} \mathrm{C}$, material melted, and migrated to the machined surface. As a result of the microscopic investigation, voids, cracks, and micro-cracks were observed. At the optimal conditions the amount and size of the defects significantly reduced [19]. Similarly, Abhilash et al. developed a failure detection and control algorithm for WEDM process and implemented on Inconel 718 alloy. After the SEM examinations of the worn wire specimens, wire degradation was detected due to the detrimental sparks. Additionally, coarser surface with voids, micro-defects, and globules were observed on the machined components. Microstructural failures were eliminated with the spark absence prediction and allowed continuous operation with increase of the surface integrity [20].

The microhardness characteristics of the wire-EDM surfaced samples at multiple points were shown in Figure 7. The values of the Vickers microhardness (HV1) was found between $221 \mathrm{HV}$ and $357 \mathrm{HV}$ along the wire-EDM surfaced NiTi sample. In the literature, as-built wire arc additive manufactured (WAAM) NiTi parts exhibited hardness distribution from 228HV to 245HV [21].

Naresh et al. investigated the connection between WEDM machining input and output parameters including pulse on/off time and peak current parameters following as material removal rate and surface roughness utilizing artificial neuro fuzzy inference system predicted model of nitinol alloy. Experimental and predicted results were compared for various inputs attributes. As a result of the high pulse on time $(50 \mu \mathrm{s})$, and high peak current $(4 \mathrm{~A})$ values generated greater amount of temperature and lead to formation of various surface attributes, like holes, cracks and solidifies debris were noticed on the machined sample [22]. Prasad et al. analyzed the effect of WEDM machining parameters on the material removal rate and surface roughness using TI6Al4V alloy. This experiment was conducted with creation of various set of parameters with Taguchi L27 orthogonal array and tested by ANOVA. The results suggested that peak current was the major responsible parameter as well as pulse on time and spark gap voltage [23]. 


\section{CONCLUSION}

In this study, the effect of wire electrical discharge machine which is used as a significant postprocessing instrument is examined for the EBM-based additive manufactured bulk NiTi samples. The as-built NiTi samples are initially cut into micro-specimen size. The micro-tensile specimens are successfully extracted from the as-built NiTi samples through the wire-EDM process for investigating the strength of the EBM-based additive manufactured NiTi shape memory alloys. The results received from scanning electron microscopy of the NiTi samples revealed that a columnar grain structure was occurred during the solidification. An irregular-shaped porous microstructure is also observed in the SEM micrographs. Vickers microhardness (HV1) distribution was found between 221HV and 357HV along the wire-EDM surfaced NiTi samples. The Cu contamination on the surface of the NiTi samples can be attributed to the WEDM cutting process. An extensive experimental study on the effect of processing parameters such as pulse on time and peak current is planned for future work.

\section{REFERENCES}

1. Sharma S., Vates U. K., Bansal A., "Parametric optimization in wire EDM of D2 tool steel using Taguchi method", Materials Today: Proceedings, Vol. 45, Pages 757-763, 2021.

2. Zakaria K., Ismail Z., Redzuan N., "Dalgarno K.W., "Effect of wire EDM cutting parameters for evaluating of Additive Manufacturing Hybrid Metal Material”, Procedia Manufacturing, Vol. 2, Pages 532-537, 2015.

3. Lexcellent C., "Shape memory alloys handbook", Pages 230-326, Wiley, London, 2013.

4. Antonucci V., Martone A., "Phenomenology of shape memory alloys, Shape memory alloy engineering", ISBN 978-0-08-099920-3, Pages 33-56, Elsevier, 2015.

5. Engeberg E.D., Dilibal S., Vatani M., Choi J., Lavery J., "Anthropomorphic finger antagonistically actuated by SMA plates", Bioinspiration Biomimetics, Vol. 10, 2015.

6. Sun L., Huang W. M., Ding Z., Zhao Y., Wang C.C., Purnawali H., Tang C., "Stimulus-responsive shape memory materials: A review", Materials and Design, Vol. 33, Pages 577-640, 2012.

7. Xu X., Lin X., Yang M., Chen J., Huang W., "Microstructure evaluation in laser solid forming of Ti-50 wt\% Ni alloy", Journal of Alloys and Compounds, Vol. 480, Pages 782-787, 2009.

8. Tan L, Dodd R.A., Crone W.C., "Corrosion and wear-corrosion behavior of NiTi modified by plasma source ion implantation", Biomaterials, Vol. 24, Pages 3931-3939, 2003.

9. Sadrnezhaad S.K., Ahmadi E., Malekzadeh M., "Mechanism of reaction of molten NiTi with EBM graphite crucible", Materials Science and Technology, Vol. 25, Pages 699-706, 2009.

10. Sames W., Unocic K.A., Dehoff R.R., Lolla T., Babu S.S., "Thermal effects on microstructural heterogeneity of Inconel 718 materials fabricated by electron beam melting”, J. Mater. Res., Vol. 29, pp. 1920-1930, 2014.

11. Dilibal S., "Stabilized actuation of a novel NiTi shape memory alloy actuated flexible structure under thermal loading". Materiali in Tehnologije, Vol. 5, Pages 599-605, 2018.

12. Mwangi J.W., Nguyen L.T., Bui V.D., Berger T., Zeidler H., Schubert A., "Nitinol manufacturing and micromachining: A review of processes and their suitability in processing medical-grade nitinol", Journal of Manufacturing Processes, Vol. 38, Pages 355-369, 2019.

13. Ozaner O.C., Dursun G., Akbulut G., "Effects of wire-EDM parameters on the surface integrity and mechanical characteristics of additively manufactured Inconel 939”, Materials Today: Proceedings, Vol. 38, Pages 1861-1865, 2021.

14. Naveed N., "Experimental study of the effects of wire EDM on the characteristics of ferritic steel, at a microscale on the contour cut surface", Metall. Res. Technol., Vol. 115, Pages 413-424, 2018. 
15. Tosun N., Cogun C., Inan A., "The effect of cutting parameters on workpiece surface roughness in wire EDM. Machining Science and Technology”, Vol. 7, Pages 209-219, 2003.

16. Altug-Peduk G., Dilibal S., Harrysson O., Ozbek S., West H., "Characterization of Ni-Ti alloy powders for use in additive manufacturing”, Russian Journal of Non-Ferrous Metals”, Vol. 59, Pages 433-439, 2018.

17. Altug-Peduk G., Dilibal S., Harrysson O., Ozbek S., "Experimental investigation on the EBM-based additively manufactured prismatic nickel-titanium SMA components", Russian Journal of Non-Ferrous Metals Vol. 62, Paged 357-367, 2021.

18. Roth R., Coemert S., Burkhardt S., Rodewald K.S., Lueth T.C., “A Process towards eliminating cytotoxicity by removal of surface contamination from electrical discharge machined Nitinol”, Procedia CIRP, Vol. 89, Pages 45-51, 2020.

19. Roy B.K., Kumara A., Sahua D.R., Roy A.M., "Wire electrical discharge machining characteristics of Nitinol-60 shape memory alloy", Materials Today: Proceedings, Vol. 22, Pages 2860-2869, 2020.

20. Abhilash P.M., Chakradhar D., "Failure detection and control for wire EDM process using multiple sensors", CIRP Journal of Manufacturing Science and Technology, Vol. 33, Pages 315-326, 2021.

21. Zeng Z., Cong B.Q., Oliveira J.P., Ke W.C, Schell N., Peng B., Qi Z.W., Ge F.G, Zhang W., Ao S.S., "Wire and arc additive manufacturing of a Ni-rich NiTi shape memory alloy: Microstructure and mechanical properties", Additive Manufacturing, Vol. 32, Pages 1-10, 2020.

22. Naresh C., Bose P.S.C., Rao C.S.P., "ANFIS based predictive model for wire edm responses involving material removal rate and surface roughness of Nitinol alloy", Materials Today: Proceedings, Vol. 33, Pages 93-101, 2020.

23. Prasad A.V.S R., Ramji K., Kolli M., “An experimental investigation on machining parameters of titanium alloy using WEDM”, Materials Today: Proceedings, Vol.18, Pages 12-16, 2019. 